\title{
A Systematic Overview of Reviews for Complementary and Alternative Therapies in the Treatment of the Fibromyalgia Syndrome
}

\author{
Romy Lauche, ${ }^{1}$ Holger Cramer, ${ }^{1}$ Winfried Häuser, ${ }^{2,3}$ Gustav Dobos, ${ }^{1}$ and Jost Langhorst ${ }^{1}$ \\ ${ }^{1}$ Department of Internal and Integrative Medicine, Kliniken Essen-Mitte, Faculty of Medicine, University of Duisburg-Essen, \\ 45276 Essen, Germany \\ ${ }^{2}$ Department of Internal Medicine 1, Klinikum Saarbrücken, 66119 Saarbrücken, Germany \\ ${ }^{3}$ Department of Psychosomatic Medicine and Psychotherapy, Munich University of Technology (TUM), 81865 München, Germany \\ Correspondence should be addressed to Romy Lauche; r.lauche@kliniken-essen-mitte.de
}

Received 5 January 2015; Accepted 26 May 2015

Academic Editor: Antonella Fioravanti

Copyright (C) 2015 Romy Lauche et al. This is an open access article distributed under the Creative Commons Attribution License, which permits unrestricted use, distribution, and reproduction in any medium, provided the original work is properly cited.

\begin{abstract}
Objectives. This systematic overview of reviews aimed to summarize evidence and methodological quality from systematic reviews of complementary and alternative medicine (CAM) for the fibromyalgia syndrome (FMS). Methods. The PubMed/MEDLINE, Cochrane Library, and Scopus databases were screened from their inception to Sept 2013 to identify systematic reviews and meta-analyses of CAM interventions for FMS. Methodological quality of reviews was rated using the AMSTAR instrument. Results. Altogether 25 systematic reviews were found; they investigated the evidence of CAM in general, exercised-based CAM therapies, manipulative therapies, Mind/Body therapies, acupuncture, hydrotherapy, phytotherapy, and homeopathy. Methodological quality of reviews ranged from lowest to highest possible quality. Consistently positive results were found for tai chi, yoga, meditation and mindfulness-based interventions, hypnosis or guided imagery, electromyogram (EMG) biofeedback, and balneotherapy/hydrotherapy. Inconsistent results concerned qigong, acupuncture, chiropractic interventions, electroencephalogram (EEG) biofeedback, and nutritional supplements. Inconclusive results were found for homeopathy and phytotherapy. Major methodological flaws included missing details on data extraction process, included or excluded studies, study details, and adaption of conclusions based on quality assessment. Conclusions. Despite a growing body of scientific evidence of CAM therapies for the management of FMS systematic reviews still show methodological flaws limiting definite conclusions about their efficacy and safety.
\end{abstract}

\section{Introduction}

The fibromyalgia syndrome (FMS) is a chronic condition that is characterized by chronic widespread pain, fatigue, sleep disorders, cognitive disturbances, and physical and psychological distress $[1,2]$. Not only did the diagnostic criteria for FMS change over time but also they are heterogeneous according to the classification system used. While a diagnosis according to the earlier criteria of the American College of Rheumatology required the presence of a specific number of tender points, more recent guidelines did not define tender points but focused on the presence of widespread pain locations $[1,2]$. It was estimated that between 2.9 and $3.8 \%$ of the general population in Europe and the US are affected [3-5], with the majority of patients in clinical settings being female [2].

Many patients with fibromyalgia utilize complementary and alternative therapies in addition to conventional medicine. The most recent German consumers report indicated that almost every FMS patient had used at least one CAM therapy for the management of FMS in the past, with the majority being heat application or thermal baths $(67.0 \%)$, CAM medications such as homeopathy, dietary supplements, and vitamins $(35.2 \%)$, some kind of diet $(34.6 \%)$, toolbased physical therapies such as acupuncture $(28.5 \%)$, and meditative exercises such as yoga or tai chi (18.4\%) [6]. 
In an internet survey with US American FMS patients CAM treatments were also highly utilized [7]. Contrary to the highly frequent use data on efficacy and safety are sparse. Such data are however necessary to judge its value within the treatment regimen. Without reliable information such therapies that might benefit FMS patients might also not be recognized by decision makers.

In the current German guideline for the treatment of the fibromyalgia only meditative exercise techniques, that is, yoga, tai chi, or qigong, among others, received a strong recommendation followed by acupuncture with an open recommendation. All other complementary therapies were not recommended when used as monotherapies.

Systematic reviews are literature reviews focusing on the synthesis of evidence from clinical research; they are the basis of evidence-based medicine. Systematic reviews are considered at the highest level of medical evidence; only data from systematic reviews will receive la-evidence according to the levels of evidence from the Centre of Evidence-Based Medicine in Oxford [8]. However, no systematic review is like the other, and this especially concerns the methodological quality [9].

For FMS numerous reviews on the effects of complementary and alternative therapies have been published, often with contradictory results. This systematic overview of reviews aimed to provide an overview of evidence from systematic reviews of CAM for fibromyalgia and to determine methodological quality of those reviews.

\section{Materials and Methods}

2.1. Protocol and Registration. This review was planned and conducted in accordance with the Preferred Reporting Items for Systematic Reviews and Meta-Analyses (PRISMA) guidelines [10]. The protocol was not registered in any database.

2.2. Eligibility Criteria. To be eligible for this overview of systematic reviews, reviews were required to meet the following conditions.

(1) Types of Reviews. Systematic reviews with or without metaanalysis were eligible. All reviews claiming to be systematic were included, as well as all reviews with a systematic literature search aiming for a comprehensive overview of evidence. Reviews explicitly stating to have chosen only selected trials, for example, by personal preference, were excluded.

(2) Types of Participants. Only reviews for patients with fibromyalgia were included. Reviews for disease classes that include fibromyalgia, for example, rheumatic diseases in general, were not eligible. No restrictions regarding age, gender, conditions duration, or intensity were applied. There were also no restrictions regarding the diagnostic criteria or procedures of trials and reviews, and they were all considered eligible.

(3) Types of Interventions. Reviews on the effects of complementary and alternative (CAM) therapies were included. For the definition of CAM therapies the definition of the
US American National Institute of Health (NIH) [11] was followed; this included natural products, mind and body practices, and other health practices such as holistic medical systems. Reviews were included if they focused on a single therapy or on CAM in general. Reviews focusing on therapy classes that might include CAM therapies, for example, nonpharmacological therapies, were not considered eligible.

(4) Types of Outcomes. Reviews were eligible if they assessed at least one of the following patient-centered outcomes, namely, pain, quality of life, sleep quality, fatigue, psychological distress, well-being, and/or safety. Those outcomes were chosen because they reflect the main symptoms and complaints in FMS patients [2].

(5) Accessibility of Data. Reviews were eligible only if they were published as full papers. Only published work in peerreviewed journals was included; abstracts or unpublished work was excluded. Only reviews in English or German were eligible.

2.2.1. Literature Search. The following electronic databases were searched from their inception to September 25, 2013: PubMed/MEDLINE, Scopus, and the Cochrane Library. The literature search was constructed around search terms for "fibromyalgia syndrome," reviews, and meta-analyses and adapted for each database. For example, the following search strategy was used on the PubMed/MEDLINE database:

(Fibromyalgia [MeSH Terms] OR fibromyalgia [Title/ Abstract] OR fibrositis

[Title/Abstract] OR FMS [Title/Abstract])

\section{AND}

(Review [Publication type] OR meta-analysis [Publication type] OR systematic [Subset] OR systematic review [Title/Abstract] OR review

[Title/Abstract] OR meta-analysis [Title/Abstract]).

The reference lists of identified reviews were also searched manually for relevant articles.

2.2.2. Review Selection. At first all duplicates were removed from the references. Two reviewers (RL, HC) then screened the abstracts of the remaining papers individually and went on to obtain the full papers for potentially eligible reviews. The reviews were then checked in detail, with eligible papers being included in this overview.

2.2.3. Data Collection. Two reviewers (RL, HC) independently extracted data on reviews' characteristics (intervention, comparator, types of included studies, number of studies and patients, information on meta-analysis, risk of bias assessments, and safety). Disagreements were checked with a third reviewer (JL) and resolved by agreement.

2.2.4. Methodological Quality. Methodological quality of reviews was determined using the assessment of the methodological quality of systematic reviews (AMSTAR) $[12,13]$. 


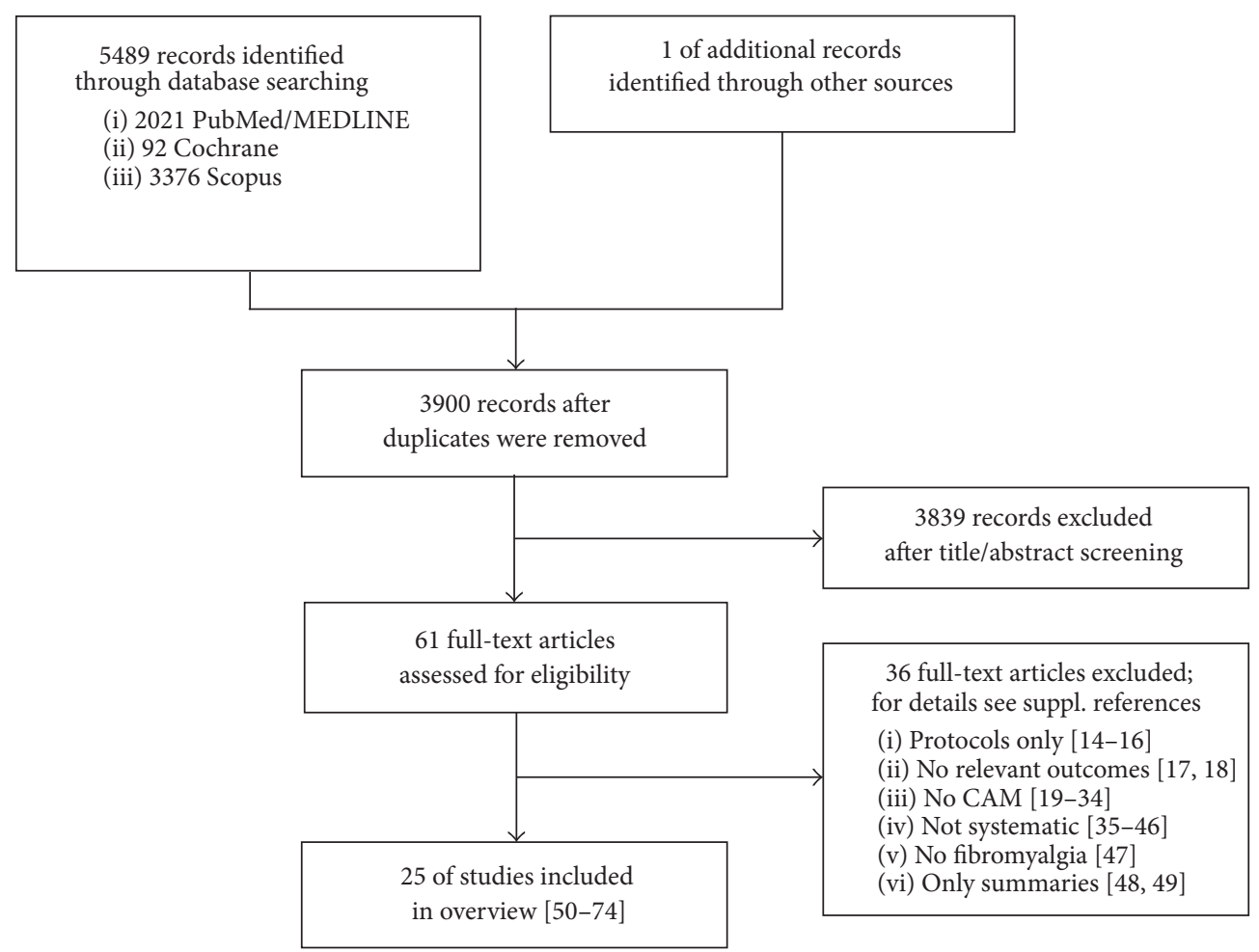

FIGURE 1: CONSORT flow chart of review inclusion.

The AMSTAR instrument is an 11-item assessment tool mainly for intervention reviews with good validity and reliability $[12,13]$. The AMSTAR determines whether most important contents of systematic reviews have been provided, such as an a priori design, a comprehensive literature search, information about study selection and data extraction, a list of included and excluded studies, characteristics of studies, a quality assessment of included studies, an appropriate method of combining findings or forming conclusions, and conflict of interests statements.

\section{Results}

3.1. Literature Search. The literature search and cross-reference search retrieved 5489 records, of which 1590 were duplicates (Figure 1). After abstract screening, 3839 records were excluded. Of the remaining 61 articles that were assessed as full text, 36 were excluded for the following reasons: three of them were only protocols [14-16], two did not report relevant outcomes [17, 18], 16 did not fit the reviews definition of CAM therapies as stated in the inclusion criteria [19-34], 12 reviews were not systematic [35-46], one did not review trials on fibromyalgia [47], and two publications were only summaries of the results of reviews and medical guidelines $[48,49]$.

3.2. Review Characteristics. Finally 25 reviews could be included; characteristics are presented in Table 1.
The trials were published in the years $2000(N=1), 2003$ $(N=1), 2007(N=1), 2008(N=1), 2009$ ( $N=5), 2010$ $(N=4), 2011(N=2), 2012(N=2)$, and $2013(N=8)$.

Reviews investigated the following therapies: complementary and alternative therapies in general $(N=4)[50-$ 53], exercised-based therapies $(N=4)$ [54-57], manipulative therapies $(N=3)[58-60]$, Mind/Body therapies $(N=5)$ [61-65], acupuncture $(N=4)$ [66-69], balneotherapy $(N=$ 3) [70-72], phytotherapy $(N=1)$ [73], and homeopathy $(N=1)[74]$.

RCTs and quasi-RCTs only were included by 17 reviews $[50,51,53,55,56,58,62-64,66-69,73,74]$; the other reviews also included controlled clinical trials [52, 54, 61, 65], observational trials [70], or any kind of study/review [57, 59, 60]. Reviews included from 4 to 60 trials with a total patient sample from 163 to 2897 . Of the 25 reviews only 11 conducted meta-analyses.

All but three reviews $[59,68,70]$ assessed the risk of bias of included trials, nine used the Jadad score [51, 54, 57, 58, 63, $64,69,73,74]$, three used the Cochrane risk of bias assessment $[56,65,66]$, three used the van Tulder scale $[67,71,72]$, four applied self-adapted instruments or partial instruments $[53,55,62]$, one the Oxford rating scale [60], one the Consort rating scale [52] and one the Scale for rating of quality of psychological trials in pain [61]. Only two reviews explicitly reported methods for formulating recommendation [56, 65], and both used the GRADE approach [75].

Quality assessment revealed maximal differences between the reviews; while some were of highest quality, others did only receive 2 of 11 possible points; see Table 2 . While 


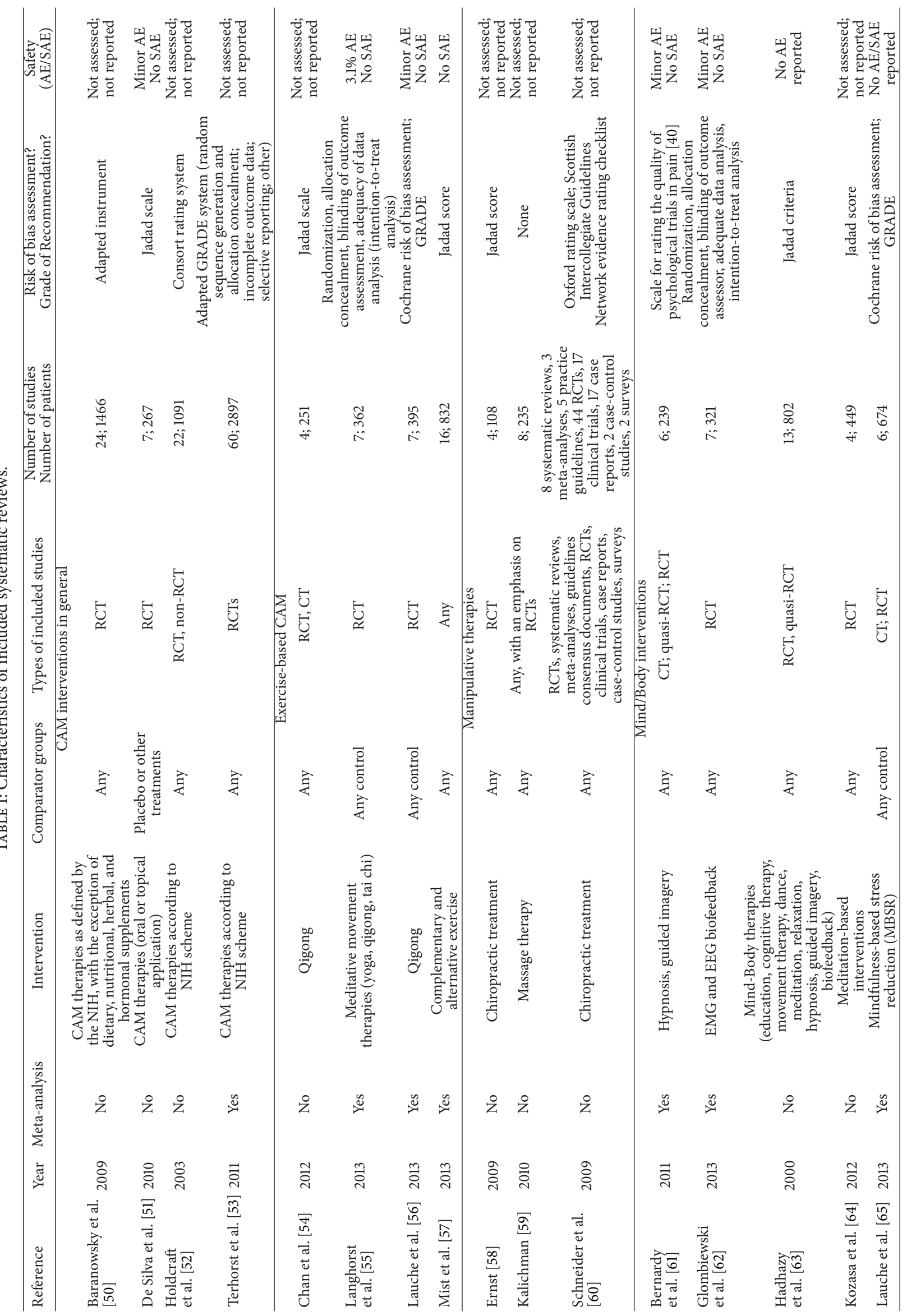




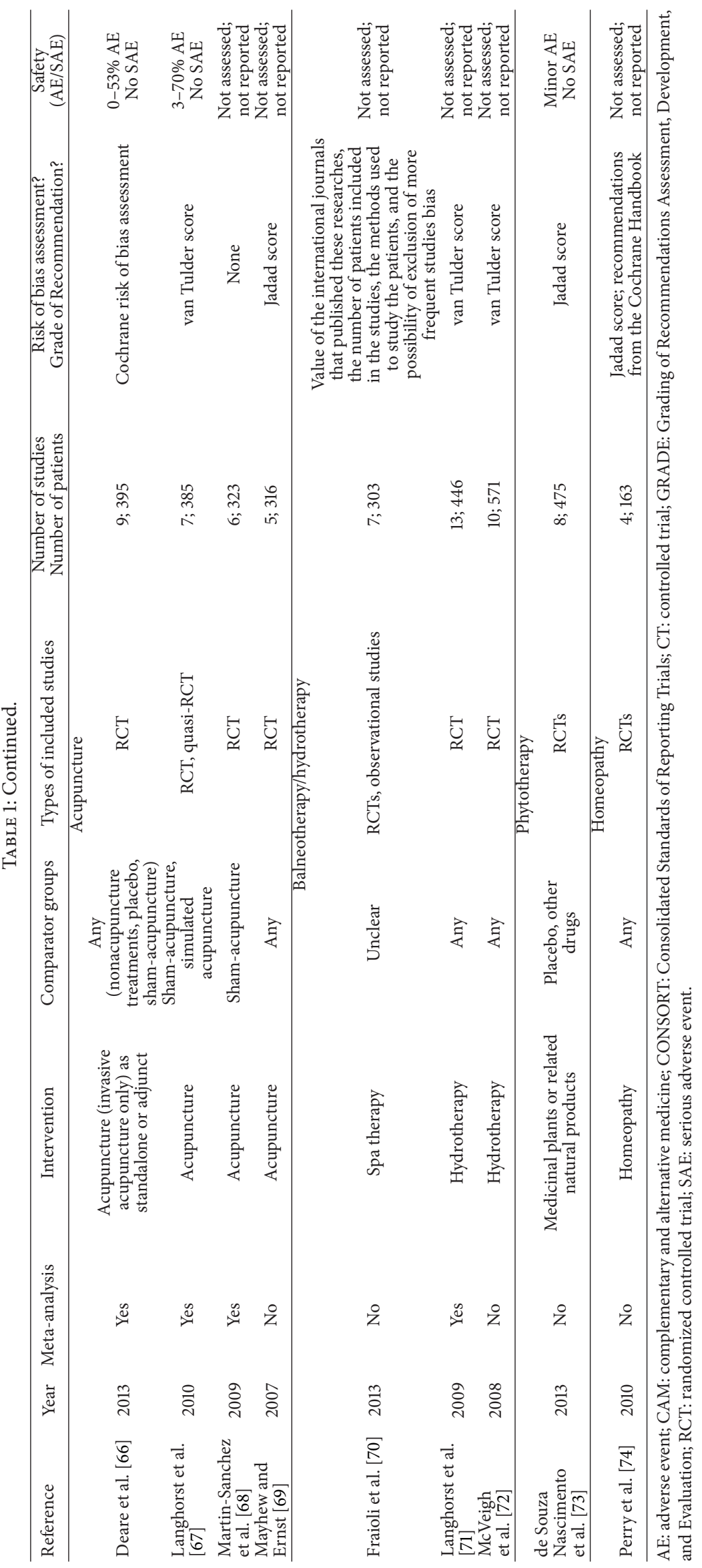




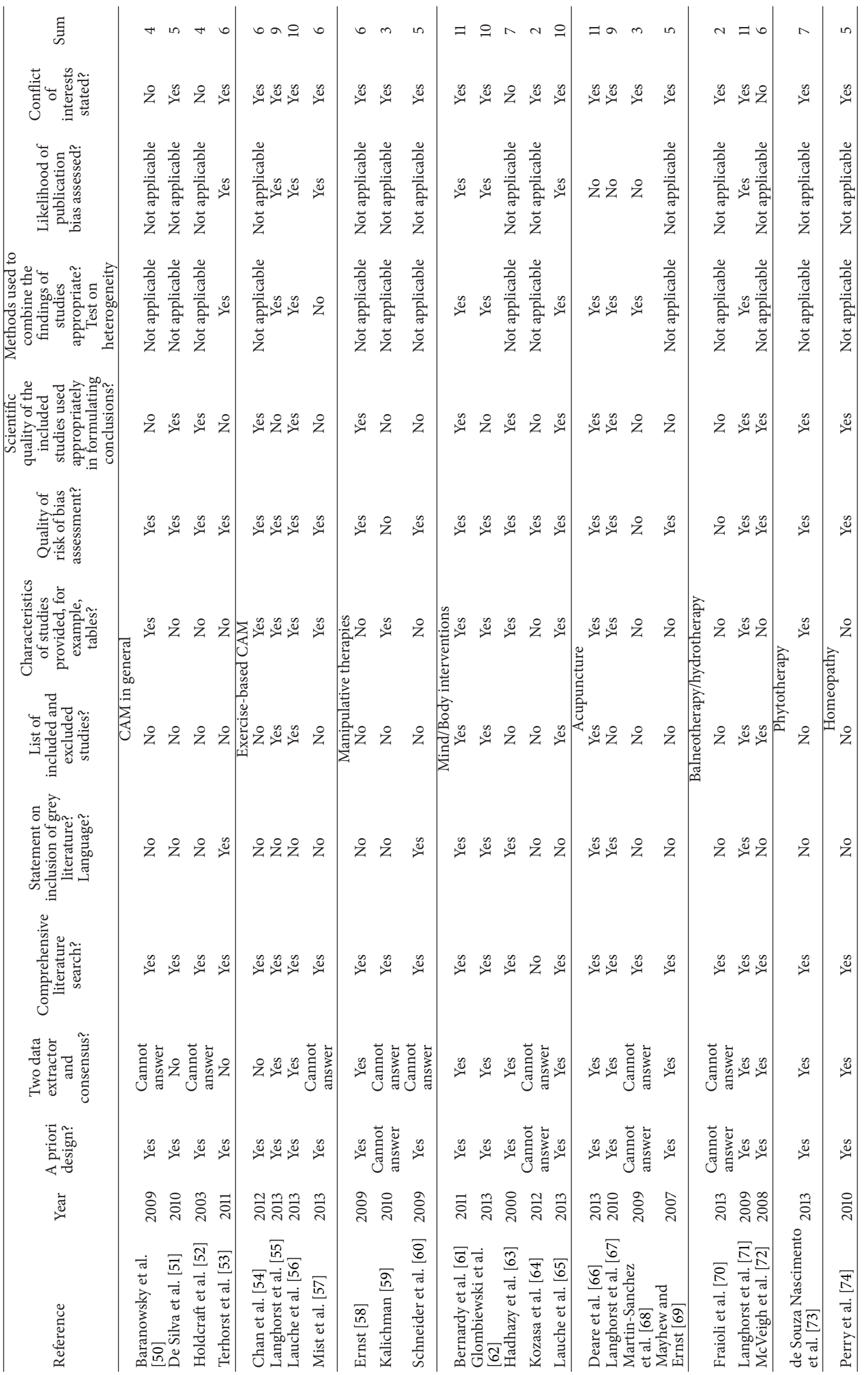


all reviews conducted a systematic literature search (which explicitly was an inclusion criterion), some of the reviews did not state an a priori design $(N=3)[59,64,68]$, and in some reviews either data extraction was not described or data were not extracted independently by two people $(N=$ 12) $[50-54,57,59,60,64,68]$. Only seven reviews listed included and excluded studies [55, 56, 61, 62, 65, 71, 72], and comprehensive study characteristics were provided by 14 reviews only $[50,54-57,59,61-63,65,67,71,73]$. Risk of bias assessment was conducted in all but two reviews $[59,68]$, but the scientific quality was not appropriately included in formulating conclusions in nine of those reviews using a risk of bias assessment $[50,53,55,57,59,60,62,64,69]$. Of those reviews conducting meta-analyses $[53,55-57,61,62,65-$ $68,71]$ only one used nonappropriate methods to combine study findings [57].

Likelihood of publication bias was not assessed in the majority of reviews, and two reviews with meta-analysis lacked this information $[67,68]$. Conflict of interests was stated in most reviews with only 3 exceptions $[52,63,72]$.

3.3. Results of Reviews. Evidence for or against the respective interventions is summarized in Table 3.

3.3.1. CAM in General. Altogether four reviews stated that they investigated the effects of CAM in fibromyalgia [5053], and only one of them conducted a meta-analysis [53]. The first thing that became evident was that no uniform definition of CAM exists; while Holdcraft et al. [52] and Terhorst et al. [53] followed the definition set by the NIH [11], Baranowsky et al. [50] excluded dietary, nutritional, herbal, or hormonal supplements. De Silva et al. [51] on the other hand defined CAM as oral or topical preparations only. Even within the NIH definition results of literature search showed a tremendous increase in studies between 2003 and 2011, resulting in 60 RCTs in 2011 [53] compared to 22 included in 2003 [52]. Quality of CAM reviews was rather low with ranges from 4 to 6 according to the AMSTAR rating.

Most of those reviews presented separate results for single CAM treatments; therefore their results were split up and presented within the respective intervention categories.

3.3.2. Exercise-Based Interventions. Two reviews, with and without meta-analyses, investigated the effects of qigong [54, 56]. While the first review [54] concluded that it was too early to draw conclusions, one year later a second review [56] with almost twice as many studies found moderate-to-strong short-term effects on most patient relevant outcomes when compared to usual care.

Within the more comprehensive reviews results were more equivocal $[50,53,55,57]$. For yoga as well as tai chi reviews stated mainly positive results $[53,55,57]$, even though for tai chi only limited evidence was available [55]. Quality of reviews within this category was mixed with two reviews of high and two of moderate quality.

3.3.3. Manipulative Therapies. Two reviews were conducted for chiropractic management $[58,60]$ and one was conducted for massage [59], but no meta-analysis was included in either. The two reviews for chiropractic care were of moderate quality, and they found limited evidence [60] or no evidence [58] for effects of chiropractic intervention. Similar results were reported by the comprehensive reviews $[52,53]$.

The review on massage was judged to be low quality, and its conclusion was that "existing literature provides modest support for use of massage therapy in treating fibromyalgia." Holdcraft et al. [52] come to a similar conclusion, while Terhorst et al. [53] concluded that there was no evidence for effects of massage at all.

3.3.4. Mind/Body Interventions. Reviews on Mind-Body interventions investigated the effects of any treatment modality [63], meditation-based interventions [64], mindfulnessbased stress reduction (MBSR) [65], hypnosis or guided imagery [61], or biofeedback [62]; only 3 of them conducted meta-analyses $[61,62,65]$. Two comprehensive reviews also included Mind/Body interventions [50, 52]. Quality of reviews was considerable heterogeneous with a range from very low [64] to very high [61].

Almost all reviews found at least limited evidence for effects of Mind/Body interventions with the exception of biofeedback [50] and EEG biofeedback in particular [62]. Limited evidence was also found for relaxation [52] but not autogenic training [50].

3.3.5. Acupuncture. Four reviews were found for the effects of acupuncture in FMS [66-69], and three comprehensive reviews included acupuncture [50, 52, 53]. Results for acupuncture were rather varying with reviews finding strong evidence for effects on pain $[52,66,67]$, two finding no evidence for effects $[53,68]$ and two with inconclusive results $[50,69]$. Quality of reviews for acupuncture was mixed, with two low and two high quality reviews.

3.3.6. Hydrotherapy/Balneotherapy. For balneotherapy and/ or hydrotherapy three reviews were found [70-72]. Together with the comprehensive reviews $[50,52,53]$ only positive evidence of different degrees was found [50, 52, 53, 70-72]. Quality again was very different between the reviews from very low to very high quality and only one meta-analysis.

3.3.7. Phytotherapy. For phytotherapy only one review was available [73] and results indicate a need for further studies before any judgment about effects can be made. This review was of moderate quality.

3.3.8. Homeopathy. For homeopathy only one standalone review was available [74], and authors concluded that effectiveness remained unproven. From the more comprehensive reviews one was coming to the same conclusion, while three others found at least some/limited evidence [50-52].

3.3.9. Others. The comprehensive reviews also included nutritional supplements, some of which had limited evidence [52], while others were considered ineffective [53]. 
TABLE 3: Overview of conclusions for investigated therapies from included systematic reviews.

\begin{tabular}{|c|c|c|c|}
\hline Intervention & Positive evidence & Negative evidence & Inconclusive \\
\hline \multicolumn{4}{|c|}{ Mind/Body interventions } \\
\hline Mind/Body interventions in general & $\begin{array}{l}\text { (i) Effects on pain [53] } \\
\text { (ii) More effective than usual care } \\
\text { for some outcomes [63] }\end{array}$ & & \\
\hline Meditation-based interventions & $\begin{array}{l}\text { (i) Mostly positive results [50] } \\
\text { (ii) Most studies indicate } \\
\text { improvement [64] }\end{array}$ & & \\
\hline Mindfulness-based stress reduction & $\begin{array}{l}\text { Moderate short-term effects on FMS } \\
\text { key symptoms [65] }\end{array}$ & & \\
\hline Hypnosis/guided imagery & $\begin{array}{l}\text { Strong short-term effects on pain } \\
\text { [61] }\end{array}$ & & \\
\hline Biofeedback & $\begin{array}{l}\text { (i) Limited evidence for biofeedback } \\
\text { [52] } \\
\text { (ii) Moderate effects on pain for } \\
\text { EMG biofeedback [62] }\end{array}$ & $\begin{array}{l}\text { (i) No positive results [50] } \\
\text { (ii) No effects of EEG } \\
\text { biofeedback [62] }\end{array}$ & \\
\hline Relaxation & Limited evidence [52] & & \\
\hline Autogenic training & & $\begin{array}{l}\text { No effects of autogenic } \\
\text { training [50] }\end{array}$ & \\
\hline
\end{tabular}

\section{Exercised-based CAM}

(i) Moderate-to-strong short-term effects on FMS key symptoms [56]

Qigong

Tai Chi (ii) Moderate effect on functional disability [57]

(iii) A positive trend [53]

(i) Strong effect on functional disability [57]

(ii) Moderate effect on sleep quality

[55]

(iii) One study in favor of tai chi [53]

(i) Significant effects on pain,

fatigue, depression, and quality of

life [55]

(ii) Moderate effect on functional disability [57]

Manipulative therapies

\begin{tabular}{|c|c|c|c|}
\hline Chiropractic interventions & Limited evidence [60] & $\begin{array}{l}\text { (i) No positive evidence [58] } \\
\text { (ii) Insufficient evidence for } \\
\text { benefit [52] }\end{array}$ & Not enough evidence [53] \\
\hline Massage & $\begin{array}{l}\text { (i) Moderate evidence [52] } \\
\text { (ii) Massage is beneficial for patients } \\
\text { with fibromyalgia [59] }\end{array}$ & Ineffective [53] & \\
\hline \multicolumn{4}{|c|}{ Acupuncture } \\
\hline & $\begin{array}{l}\text { (i) Strong evidence [52] } \\
\text { (ii) Strong evidence for small } \\
\text { short-term effects on pain [67] } \\
\text { (iii) Low-to-moderate evidence for } \\
\text { acupuncture compared to usual care } \\
\text { or standard care [66] }\end{array}$ & $\begin{array}{l}\text { (i) Ineffective [53] } \\
\text { (ii) No evidence for } \\
\text { effectiveness [68] }\end{array}$ & $\begin{array}{l}\text { (i) Mixed quality [50] } \\
\text { (ii) Effectiveness not yet } \\
\text { supported, mixed evidence } \\
\text { [69] }\end{array}$ \\
\hline \multicolumn{4}{|c|}{ Balneotherapy/hydrotherapy } \\
\hline & $\begin{array}{l}\text { (i) Positive evidence [50] } \\
\text { (ii) Limited evidence [52] } \\
\text { (iii) Effects on pain [53] } \\
\text { (iv) Moderate evidence for pain [69] }\end{array}$ & & \\
\hline & $\begin{array}{l}\text { (v) Strong evidence [72] } \\
\text { (vi) Appears efficacious [70] }\end{array}$ & & \\
\hline
\end{tabular}

(i) No positive results [50] Too early to draw

(ii) No evidence of effects [55] conclusions [54] 
TABLE 3: Continued.

\begin{tabular}{|c|c|c|c|}
\hline Intervention & Positive evidence & Negative evidence & Inconclusive \\
\hline \multicolumn{4}{|c|}{ Phytotherapy } \\
\hline & & & $\begin{array}{l}\text { Unclear whether medicinal } \\
\text { products or related natural } \\
\text { products are effective [73] }\end{array}$ \\
\hline \multicolumn{4}{|c|}{ Nutritional supplements } \\
\hline & $\begin{array}{l}\text { Limited evidence for diverse } \\
\text { supplements [52] }\end{array}$ & Ineffective [53] & \\
\hline \multicolumn{4}{|c|}{ Homeopathy } \\
\hline & $\begin{array}{l}\text { (i) Positive results [50] } \\
\text { (ii) Limited evidence [52] } \\
\text { (iii) Some evidence [51] }\end{array}$ & & $\begin{array}{l}\text { (i) Not enough evidence [53] } \\
\text { (ii) Effectiveness remains } \\
\text { unproven [74] }\end{array}$ \\
\hline
\end{tabular}

3.4. Adverse Events. Adverse events were neither assessed nor reported in 14 reviews $[50,52,54,58,64,68-72,74]$. In the other reviews adverse events were mild to moderate; however as was pointed out before, many trials did not sufficiently report on adverse events.

\section{Discussion}

Altogether 25 systematic reviews investigated the effects of complementary and alternative therapies for FMS. Topics included CAM in general, exercised-based CAM therapies, manipulative therapies, Mind/Body therapies, acupuncture, balneotherapy, phytotherapy, and homeopathy. Two-thirds of the reviews included RCTs and quasi-RCTs; however a substantial number also included other study types from case reports to reviews. Only 11 reviews conducted a metaanalysis. A risk of bias assessment of included trials was included in most reviews; standardized recommendations for or against specific therapies on the other hand were used by two reviews only. Methodological quality of reviews was completely diverse ranging from lowest to highest possible quality.

4.1. Homogeneous Findings. Positive results were found for tai chi, yoga, Mind/Body interventions in general, meditationbased interventions, mindfulness-based stress reduction, hypnosis or guided imagery, and balneotherapy or hydrotherapy. Negative results were reported on autogenic training, and inconclusive findings were reported for phytotherapy, however only one review each was available for autogenic training and phytotherapy.

4.2. Heterogeneous Findings. Heterogeneous findings, that is, positive and negative findings, were reported for qigong, chiropractic interventions, biofeedback, acupuncture, and nutritional supplements. In the following we will try to determine the source of heterogeneity.

For qigong three reviews found positive evidence [53, $56,57]$, and two found negative evidence $[50,55]$. Positive reviews were associated with later publication date, higher methodological quality, and three times as many included trials as negative reviews. Therefore positive results appear to be more valid than negative results.

For chiropractic interventions there is one review with limited evidence [60] versus two reviews that do not find positive evidence $[52,58]$. No association between time of publication, methodological quality, and number of included trials could be found. However the positive review included all study types limiting the validity of any conclusion. Altogether for chiropractic interventions there seems to be no reliable positive evidence.

For biofeedback two reviews conclude positive results $[52,62]$ and two do not $[50,62]$. One reason might be that only one of the reviews distinguished between EEG and EMG biofeedback [62]. So while for EMG biofeedback positive results have been found, no evidence was present for EEG biofeedback.

For acupuncture the following was found: the later reviews were published, the more trials were included, the more frequent meta-analyses were conducted, and the more conclusive results became. Secondly, results for quality of reviews were more diverse, but a trend towards higher quality reviews coming to a positive conclusion can be found. Therefore one could assume that acupuncture might be effective for FMS.

For nutritional supplement one review from 2003 [52] found positive results while one review from 2011 [53] found negative evidence. One could assume that nutritional supplements are not effective in the treatment of FMS.

Results of the overview are mostly in line with a previous overview [45]; however there were also substantial differences. While Terry et al. [45] only included 5 reviews, we could include 25 . Results on hydrotherapy are positive in both overviews; the results for massage however are more diverse, which might have been a result of the inclusion of massage into the category of manual therapies. According to Terry et al. [45] also the use of acupuncture appears promising. In our review we also found that especially high quality reviews supported positive effects of acupuncture, and this finding might however be influenced by other factors such as time which might be connected to better methodological training or more eligible trials. For homeopathy on the other hand 
the quality of evidence was not supportive of positive or promising results yet.

The evidence found in this review is not necessarily in line with current treatment guidelines; for example, there is conflicting or lacking evidence for qigong, tai chi, or yoga; nevertheless they are explicitly recommended in the German guideline [75] because physical activity and self-care are considered important therapeutic goals in fibromyalgia patients. Positive evidence on massage on the other hand did not lead to a positive recommendation per se; instead availability, costs, and its negative influence on self-efficacy and coping behavior led to downgrading of recommendation.

4.3. Limitations. Despite all previous findings and conclusion, there are several limitations that might limit the results of this overview.

The first limitation concerns the inclusion criteria of the included reviews. While some reviews explicitly included only certain CAM therapies, others conducted comprehensive reviews for CAM in general. Since the definition of CAM is not always consistent, this might lead to a different direction of each review. Two reviews aiming at the efficacy of CAM therapies in general might therefore end up in contrary conclusions merely by different definitions of CAM. Also reviews that focused on physiotherapeutic interventions or exercise in general might also have summarized evidence for single CAM interventions; however since their focus was not on CAM only, they were not included. Furthermore reviews and the trials they were based on might have used different diagnostic criteria or procedures, which also might have influenced the results.

The methodological quality of reviews is probably one of the major limitations. Quality ranged from lowest to highest possible, and quality of reviews was also associated with the direction of results. Particularly for topics with only low quality reviews available this might limit the validity of results. This might be problematic since reviews and meta-analysis are considered highest evidence standard for guideline developers.

And another limitation concerns the use of terminology when summarizing evidence, risk of bias, methodological quality, or recommendations. Most reviews used different terms that were not consistent with recommendations; this might result in misinterpretation of results and conclusions.

4.4. Implication for Further Research. In the future the number of reviews and meta-analyses will increase; this should be accompanied by increased methodological quality, if those reviews aim to influence treatment guidelines and decision makers. The more transparent and methodologically sound a review is conducted the easier it is for decision makers to rely on the results when developing treatment guidelines. The following implications, which are not limited to CAM reviews, can be made for future reviews.

The basis of a good review is a straight and relevant research question. Defining patients, interventions, comparators, outcomes, and study types before conducting a review are most essential. They are also the basis of a comprehensive literature search. All steps from literature search to conclusions must be made visible; this also includes information such as the following. Was the search limited in terms of language or publication status? Who extracted data? Why were studies excluded? What studies were finally included? How was the quality of those trials? How were results combined, for example, using a meta-analysis? How did one come up with a conclusion or recommendation? There are several guidelines available on how to report a systematic review; for example, the PRISMA statement [10] provides a comprehensive list of items to be reported in reviews and meta-analyses. There are also validated tools for risk of bias or quality assessment, for example, Cochrane tools, and for grading recommendations, for example, GRADE [76]. Since those tools are validated as a whole, they should not be altered. For several therapies such as massages blinding of patients and therapists is impossible; however this per se constitutes a possible risk of bias in those trials, which cannot be eliminated by eliminating that item from the risk of bias assessment list.

In summary, the number of reviews on CAM therapies for the management of fibromyalgia syndrome is increasing. However many reviews still show certain methodological flaws limiting definite conclusions about the efficacy of CAM therapies. Rather consistent positive results were found for tai chi, yoga, meditation- and mindfulness-based interventions, hypnosis or guided imagery, EMG biofeedback, and balneotherapy/hydrotherapy. Inconsistent results concerned qigong, acupuncture, chiropractic interventions, EEG biofeedback, and nutritional supplements. Inconclusive results were found for homeopathy and phytotherapy.

\section{Conclusion}

Despite a growing body of scientific evidence of CAM therapies for the management of FMS systematic reviews still show methodological flaws limiting definite conclusions about the efficacy and safety of those therapies.

\section{Disclaimer}

The grant source had no influence on planning, conducting, or publishing this paper.

\section{Conflict of Interests}

The authors declare that they have no conflict of interests.

\section{Acknowledgment}

This overview of review was supported by a grant from the Rut and Klaus Bahlsen Foundation. 


\section{References}

[1] W. Häuser, S. Hayo, W. Biewer et al., "Diagnosis of fibromyalgia syndrome-a comparison of Association of the Medical Scientific Societies in Germany, survey, and American College of Rheumatology criteria," Clinical Journal of Pain, vol. 26, no. 6, pp. 505-511, 2010.

[2] F. Wolfe, D. J. Clauw, M.-A. Fitzcharles et al., "The American College of Rheumatology preliminary diagnostic criteria for fibromyalgia and measurement of symptom severity," Arthritis Care and Research, vol. 62, no. 5, pp. 600-610, 2010.

[3] J. C. Branco, O. Zachrisson, S. Perrot, and Y. Mainguy, "A European multicenter randomized double-blind placebo-controlled monotherapy clinical trial of milnacipran in treatment of fibromyalgia," Journal of Rheumatology, vol. 37, no. 4, pp. 851859, 2010.

[4] R. C. Lawrence, D. T. Felson, C. G. Helmick et al., "Estimates of the prevalence of arthritis and other rheumatic conditions in the United States. Part II," Arthritis \& Rheumatism, vol. 58, no. 1, pp. 26-35, 2008.

[5] F. Wolfe, E. Brähler, A. Hinz, and W. Häuser, "Fibromyalgia prevalence, somatic symptom reporting, and the dimensionality of polysymptomatic distress: results from a survey of the general population," Arthritis Care and Research, vol. 65, no. 5, pp. 777-785, 2013.

[6] W. Häuser, E. Jung, B. Erbslöh-Möller et al., "German fibromyalgia consumer reports. Benefits and harms of fibromyalgia syndrome therapies," Schmerz, vol. 26, no. 2, pp. 150-159, 2012.

[7] R. M. Bennett, J. Jones, D. C. Turk, I. J. Russell, and L. Matallana, "An internet survey of 2,596 people with fibromyalgia," BMC Musculoskeletal Disorders, vol. 8, article 27, 2007.

[8] P. Glasziou, J. P. Vandenbroucke, and I. Chalmers, "Assessing the quality of research," The British Medical Journal, vol. 328, no. 7430, pp. 39-41, 2004.

[9] D. Moher, J. Tetzlaff, A. C. Tricco, M. Sampson, and D. G. Altman, "Epidemiology and reporting characteristics of systematic reviews," PLoS Medicine, vol. 4, no. 3, pp. 447-455, 2007.

[10] D. Moher, A. Liberati, J. Tetzlaff, D. G. Altman, and PRISMA Group, "Preferred reporting items for systematic reviews and meta-analyses: the PRISMA statement," British Medical Journal, vol. 339, Article ID b2535, 2009.

[11] National Center for Complementary and Alternative Medicine, Complementary, Alternative, or Integrative Health: What's In a Name? National Center for Complementary and Alternative Medicine, 2014, https://nccih.nih.gov/health/integrativehealth.

[12] B. J. Shea, J. M. Grimshaw, G. A. Wells et al., "Development of AMSTAR: a measurement tool to assess the methodological quality of systematic reviews," BMC Medical Research Methodology, vol. 7, article 10, 2007.

[13] B. J. Shea, C. Hamel, G. A. Wells et al., "AMSTAR is a reliable and valid measurement tool to assess the methodological quality of systematic reviews," Journal of Clinical Epidemiology, vol. 62, no. 10, pp. 1013-1020, 2009.

[14] A. Boyd, C. Bleakley, C. Gill et al., "Herbal medicinal products or preparations for neuropathic pain and fibromyalgia," Cochrane Database of Systematic Reviews, no. 5, Article ID CD010528, 2013.

[15] V. Supraha, K. Francis Damian, A. Utrobicic, H. S. Choy Ernest, D. Tenzera, and A. Kordic, Probiotics for Fibromyalgia
(Protocol), Cochrane Database of Systematic Reviews, John Wiley \& Sons, 2013.

[16] A. Theadom, M. Cropley, M. Hankins, and E. Smith Helen, Mind and Body Therapy for Fibromyalgia, Cochrane Database of Systematic Reviews, John Wiley \& Sons, 2009.

[17] M. Meeus, D. Goubert, F. De Backer et al., "Heart rate variability in patients with fibromyalgia and patients with chronic fatigue syndrome: a systematic review," Seminars in Arthritis and Rheumatism, vol. 43, no. 2, pp. 279-287, 2013.

[18] E. Ortega, J. J. García, M. E. Bote et al., "Exercise in fibromyalgia and related inflammatory disorders: known effects and unknown chances," Exercise Immunology Review, vol. 15, pp. 42-65, 2009.

[19] K. Bernardy, P. Klose, A. J. Busch, E. H. S. Choy, and W. Häuser, "Cognitive behavioural therapies for fibromyalgia syndrome," The Cochrane Database of Systematic Reviews, vol. 9, Article ID CD009796, 2012.

[20] J. Gámez-Iruela and A. Sedeño-Vidal, "Effectiveness of physiotherapy in the approach to fibromyalgia. A review of the literature," Fisioterapia, vol. 35, no. 5, pp. 224-231, 2013.

[21] J. Garcia-Campayo, J. Magdalena, R. Magallón, E. FernándezGarcía, M. Salas, and E. Andrés, "A meta-analysis of the efficacy of fibromyalgia treatment according to level of care," Arthritis Research \& Therapy, vol. 10, no. 4, article R81, 2008.

[22] S. E. Gowans and A. Dehueck, "Effectiveness of exercise in management of fibromyalgia," Current Opinion in Rheumatology, vol. 16, no. 2, pp. 138-142, 2004.

[23] S. E. Gowans and A. DeHueck, "Pool exercise for individuals with fibromyalgia," Current Opinion in Rheumatology, vol. 19, no. 2, pp. 168-173, 2007.

[24] A. Gur, "Physical therapy modalities in managemennt of fibromyalgia," Current Pharmaceutical Design, vol. 12, no. 1, pp. 29-35, 2006.

[25] M. J. Lami, M. P. Martínez, and A. I. Sánchez, "Systematic review of psychological treatment in fibromyalgia," Current Pain and Headache Reports, vol. 17, no. 7, article 345, 2013.

[26] T. B. Lima, J. M. Dias, B. F. Mazuquin et al., "The effectiveness of aquatic physical therapy in the treatment of fibromyalgia: a systematic review with meta-analysis," Clinical Rehabilitation, vol. 27, no. 10, pp. 892-908, 2013.

[27] N. M. Marlow, H. S. Bonilha, and E. B. Short, "Efficacy of transcranial direct current stimulation and repetitive transcranial magnetic stimulation for treating fibromyalgia syndrome: a systematic review," Pain Practice, vol. 13, no. 2, pp. 131-145, 2013.

[28] M. Offenbächer and G. Stucki, "Physical therapy in the treatment of fibromyalgia," Scandinavian Journal of Rheumatology, Supplement, vol. 29, no. 113, pp. 78-85, 2000.

[29] L. Perraton, Z. Machotka, and S. Kumar, "Components of effective randomized controlled trials of hydrotherapy programs for fibromyalgia syndrome: a systematic review," Journal of Pain Research, vol. 2, pp. 165-173, 2009.

[30] J. Ramel, R. Bannuru, M. Griffith, and C. Wang, "Exercise for fibromyalgia pain: a meta-analysis of randomized controlled trials," Current Rheumatology Reviews, vol. 5, no. 4, pp. 188-193, 2009.

[31] L. A. Rossy, S. P. Buckelew, N. Dorr et al., "A meta-analysis of fibromyalgia treatment interventions," Annals of Behavioral Medicine, vol. 21, no. 2, pp. 180-191, 1999.

[32] J. Sim and N. Adams, "Systematic review of randomized controlled trials of nonpharmacological interventions for fibromyalgia," The Clinical Journal of Pain, vol. 18, no. 5, pp. 324336, 2002. 
[33] D. A. Williams, "Psychological and behavioural therapies in fibromyalgia and related syndromes," Best Practice and Research: Clinical Rheumatology, vol. 17, no. 4, pp. 649-665, 2003.

[34] A. Winkelmann, W. Häuser, E. Friedel et al., "Physiotherapy and physical therapies for fibromyalgia syndrome. Systematic review, meta-analysis and guideline," Schmerz, vol. 26, no. 3, pp. 276-286, 2012.

[35] J. N. Ablin, W. Häuser, and D. Buskila, "Spa treatment (Balneotherapy) for fibromyalgia-a qualitative-narrative review and a historical perspective," Evidence-Based Complementary and Alternative Medicine, vol. 2013, Article ID 638050, 5 pages, 2013.

[36] B. M. Berman, J. Ezzo, V. Hadhazy, and J. P. Swyers, "Is acupuncture effective in the treatment of fibromyalgia?" The Journal of Family Practice, vol. 48, no. 3, pp. 213-218, 1999.

[37] A. S. de Braz, A. P. de Paula, M. F. F. M. de Diniz, and R. N. de Almeida, "Non-pharmacological therapy and complementary and alternative medicine in Fibromyalgia," Revista Brasileira de Reumatologia, vol. 51, no. 3, pp. 269-282, 2011.

[38] G. Gard, "Body awareness therapy for patients with fibromyalgia and chronic pain," Disability and Rehabilitation, vol. 27, no. 12, pp. 725-728, 2005.

[39] M. Muir, "Fibromyalgia syndrome: alternative analyses and treatments, part 2," Alternative \& Complementary Therapies, vol. 5, no. 3, pp. 149-157, 1999.

[40] M. Muir and K. Ballen, "Fibromyalgia Syndrome: alternative analyses and treatments, part 1," Alternative and Complementary Therapies, vol. 5, no. 2, pp. 79-84, 1999.

[41] N. D. S. Pinto, M. D. O. B. Monteiro, D. N. Paiva et al., "Fibromyalgia and the relevance of the whole-body vibration exercises in vibratory platforms: a short review," Brazilian Archives of Biology and Technology, vol. 55, no. 1, pp. 61-67, 2012.

[42] S. Ryan, "Fibromyalgia: an overview and comparison of treatment options," British Journal of Nursing, vol. 20, no. 16, pp. 991995, 2011.

[43] M. Saad and R. De Medeiros, "Complementary therapies for fibromyalgia syndrome-a rational approach topical collection on fibromyalgia," Current Pain and Headache Reports, vol. 17, no. 8, 2013.

[44] A. J. Sarac and A. Gur, "Complementary and alternative medical therapies in fibromyalgia," Current Pharmaceutical Design, vol. 12, no. 1, pp. 47-57, 2006.

[45] R. Terry, R. Perry, and E. Ernst, "An overview of systematic reviews of complementary and alternative medicine for fibromyalgia," Clinical Rheumatology, vol. 31, no. 1, pp. 55-66, 2012.

[46] L. Zheng and K. Faber, "Review of the Chinese medical approach to the management of fibromyalgia," Current Pain and Headache Reports, vol. 9, no. 5, pp. 307-312, 2005.

[47] N. K. Eccles, "A critical review of randomized controlled trials of static magnets for pain relief," Journal of Alternative and Complementary Medicine, vol. 11, no. 3, pp. 495-509, 2005.

[48] J. Langhorst, W. Häuser, K. Bernardy et al., "Complementary and alternative therapies for fibromyalgia syndrome. Systematic review, meta-analysis and guideline," Schmerz, vol. 26, no. 3, pp. 311-317, 2012.

[49] J. Langhorst, W. Häuser, D. Irnich et al., "Alternative and complementary therapies in fibromyalgia syndrome," Schmerz, vol. 22, no. 3, pp. 324-333, 2008.
[50] J. Baranowsky, P. Klose, F. Musial, W. Haeuser, G. Dobos, and J. Langhorst, "Qualitative systemic review of randomized controlled trials on complementary and alternative medicine treatments in fibromyalgia," Rheumatology International, vol. 30, no. 1, pp. 1-21, 2009.

[51] V. De Silva, A. El-Metwally, E. Ernst, G. Lewith, and G. J. Macfarlane, "Evidence for the efficacy of complementary and alternative medicines in the management of fibromyalgia: a systematic review," Rheumatology, vol. 49, no. 6, pp. 1063-1068, 2010.

[52] L. C. Holdcraft, N. Assefi, and D. Buchwald, "Complementary and alternative medicine in fibromyalgia and related syndromes," Best Practice and Research: Clinical Rheumatology, vol. 17, no. 4, pp. 667-683, 2003.

[53] L. Terhorst, M. J. Schneider, K. H. Kim, L. M. Goozdich, and C. S. Stilley, "Complementary and alternative medicine in the treatment of pain in fibromyalgia: a systematic review of randomized controlled trials," Journal of Manipulative and Physiological Therapeutics, vol. 34, no. 7, pp. 483-496, 2011.

[54] C. L. W. Chan, C.-W. Wang, R. T. H. Ho, S.-M. Ng, E. T. C. Ziea, and V. T. Wong, "Qigong exercise for the treatment of fibromyalgia: a systematic review of randomized controlled trials," Journal of Alternative and Complementary Medicine, vol. 18, no. 7, pp. 641-646, 2012.

[55] J. Langhorst, P. Klose, G. J. Dobos, K. Bernardy, and W. Häuser, "Efficacy and safety of meditative movement therapies in fibromyalgia syndrome: a systematic review and meta-analysis of randomized controlled trials," Rheumatology International, vol. 33, no. 1, pp. 193-207, 2013.

[56] R. Lauche, H. Cramer, W. Häuser, G. Dobos, and J. Langhorst, "A systematic review and meta-analysis of qigong for the fibromyalgia syndrome," Evidence-Based Complementary and Alternative Medicine, vol. 2013, Article ID 635182, 12 pages, 2013.

[57] S. D. Mist, K. A. Firestone, and K. D. Jones, "Complementary and alternative exercise for fibromyalgia: a meta-analysis," Journal of Pain Research, vol. 6, pp. 247-260, 2013.

[58] E. Ernst, "Chiropractic treatment for fibromyalgia: a systematic review," Clinical Rheumatology, vol. 28, no. 10, pp. 1175-1178, 2009.

[59] L. Kalichman, "Massage therapy for fibromyalgia symptoms," Rheumatology International, vol. 30, no. 9, pp. 1151-1157, 2010.

[60] M. Schneider, H. Vernon, G. Ko, G. Lawson, and J. Perera, "Chiropractic management of fibromyalgia syndrome: a systematic review of the literature," Journal of Manipulative and Physiological Therapeutics, vol. 32, no. 1, pp. 25-40, 2009.

[61] K. Bernardy, N. Füber, P. Klose, and W. Häuser, "Efficacy of hypnosis/guided imagery in fibromyalgia syndrome-a systematic review and meta-analysis of controlled trials," $B M C$ Musculoskeletal Disorders, vol. 12, article 133, 2011.

[62] J. A. Glombiewski, D. Buskila, and W. Häuser, "Efficacy of EMG- and EEG-biofeedback in fibromyalgia syndrome: a metaanalysis and a systematic review of randomized controlled trials," Evidence-Based Complementary and Alternative Medicine, vol. 2013, Article ID 963741, 11 pages, 2013.

[63] V. A. Hadhazy, J. Ezzo, P. Creamer, and B. M. Berman, "Mindbody therapies for the treatment of fibromyalgia. A systematic review," The Journal of Rheumatology, vol. 27, no. 12, pp. 29112918, 2000.

[64] E. H. Kozasa, L. H. Tanaka, C. Monson, S. Little, F. C. Leao, and M. P. Peres, "The effects of meditation-based interventions on the treatment of fibromyalgia," Current Pain and Headache Reports, vol. 16, no. 5, pp. 383-387, 2012. 
[65] R. Lauche, H. Cramer, G. Dobos, J. Langhorst, and S. Schmidt, "A systematic review and meta-analysis of mindfulness-based stress reduction for the fibromyalgia syndrome," Journal of Psychosomatic Research, vol. 75, no. 6, pp. 500-510, 2013.

[66] J. C. Deare, Z. Zheng, C. C. Xue et al., "Acupuncture for treating fibromyalgia," The Cochrane Database of Systematic Reviews, vol. 5, Article ID CD007070, 2013.

[67] J. Langhorst, P. Klose, F. Musial, D. Irnich, and W. Häuser, "Efficacy of acupuncture in fibromyalgia syndrome: a systematic review with a meta-analysis of controlled clinical trials," Rheumatology, vol. 49, no. 4, pp. 778-788, 2010.

[68] E. Martin-Sanchez, E. Torralba, E. Díaz-Domínguez, A. Barriga, and J. L. R. Martin, "Efficacy of acupuncture for the treatment of fibromyalgia: systematic review and meta-analysis of randomized trials," Open Rheumatology Journal, vol. 3, pp. 25-29, 2009.

[69] E. Mayhew and E. Ernst, "Acupuncture for fibromyalgia-a systematic review of randomized clinical trials," Rheumatology, vol. 46, no. 5, pp. 801-804, 2007.

[70] A. Fraioli, M. Grassi, G. Mennuni et al., "Clinical researches on the efficacy of spa therapy in fibromyalgia. A systematic review," Annali dell'Istituto Superiore di Sanita, vol. 49, no. 2, pp. 219-229, 2013.

[71] J. Langhorst, F. Musial, P. Klose, and W. Häuser, "Efficacy of hydrotherapy in fibromyalgia syndrome-a meta-analysis of randomized controlled clinical trials," Rheumatology, vol. 48, no. 9, pp. 1155-1159, 2009.

[72] J. G. McVeigh, H. McGaughey, M. Hall, and P. Kane, "The effectiveness of hydrotherapy in the management of fibromyalgia syndrome: a systematic review," Rheumatology International, vol. 29, no. 2, pp. 119-130, 2008.

[73] S. de Souza Nascimento, J. M. Desantana, F. K. Nampo et al., "Efficacy and safety of medicinal plants or related natural products for fibromyalgia: a systematic review," Evidence-Based Complementary and Alternative Medicine, vol. 2013, Article ID 149468, 10 pages, 2013.

[74] R. Perry, R. Terry, and E. Ernst, "A systematic review of homoeopathy for the treatment of fibromyalgia," Clinical Rheumatology, vol. 29, no. 5, pp. 457-464, 2010.

[75] M.-A. Fitzcharles, Y. Shir, J. N. Ablin et al., "Classification and clinical diagnosis of fibromyalgia syndrome: recommendations of recent evidence-based interdisciplinary guidelines," Evidence-Based Complementary and Alternative Medicine, vol. 2013, Article ID 528952, 9 pages, 2013.

[76] G. H. Guyatt, A. D. Oxman, G. E. Vist et al., "GRADE: an emerging consensus on rating quality of evidence and strength of recommendations," British Medical Journal, vol. 336, no. 7650, pp. 924-926, 2008. 


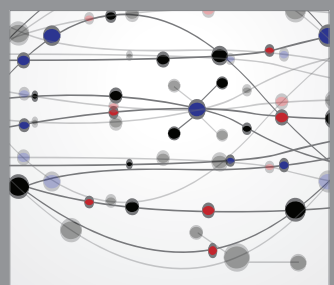

The Scientific World Journal
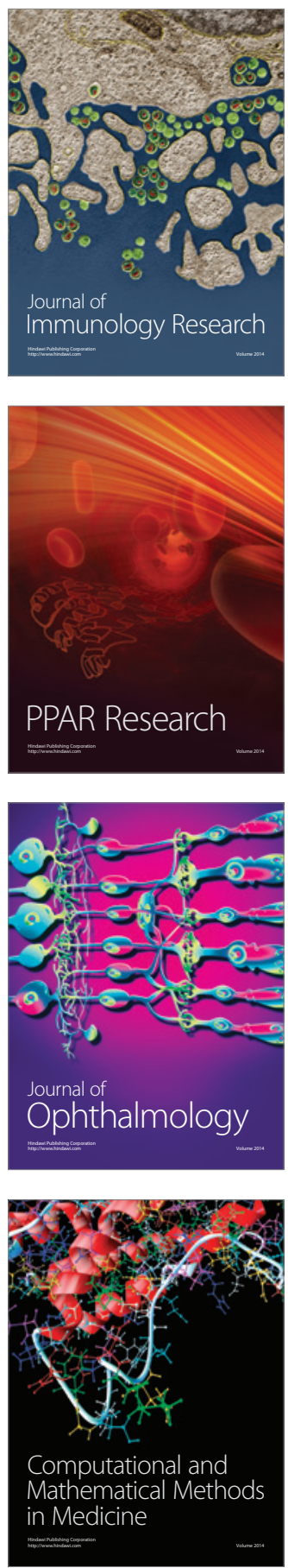

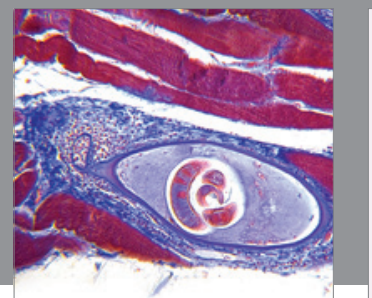

Gastroenterology

Research and Practice
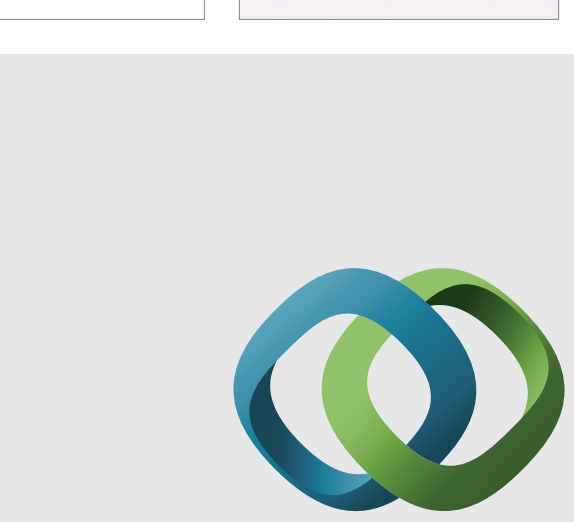

\section{Hindawi}

Submit your manuscripts at

http://www.hindawi.com
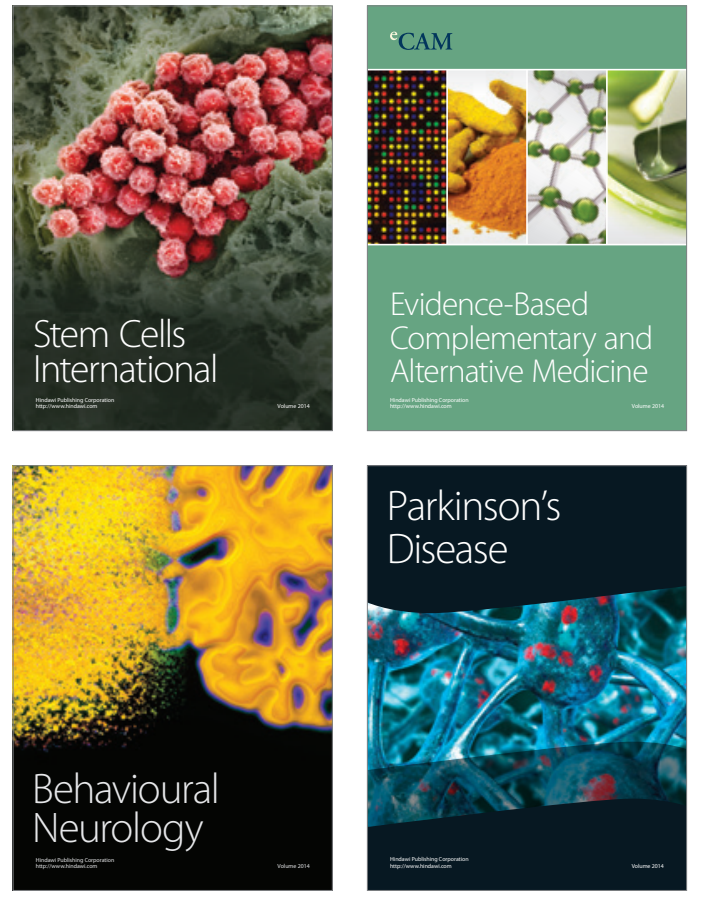
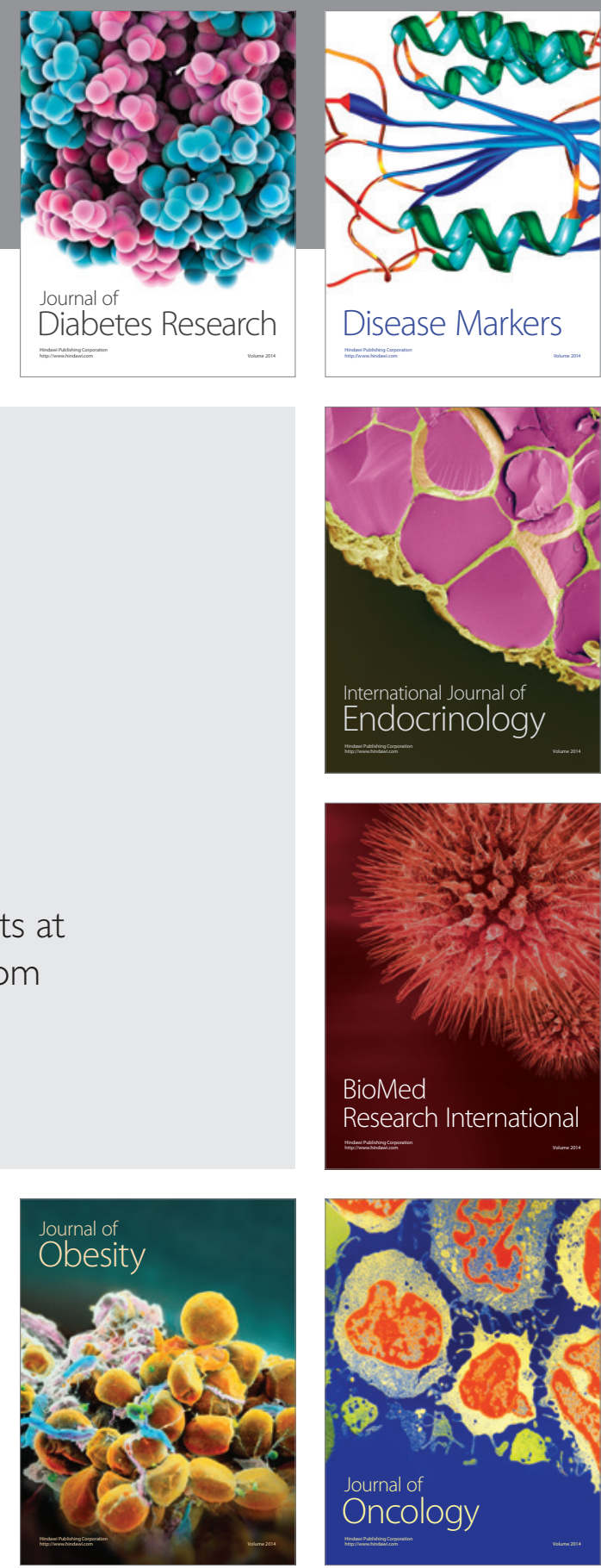

Disease Markers
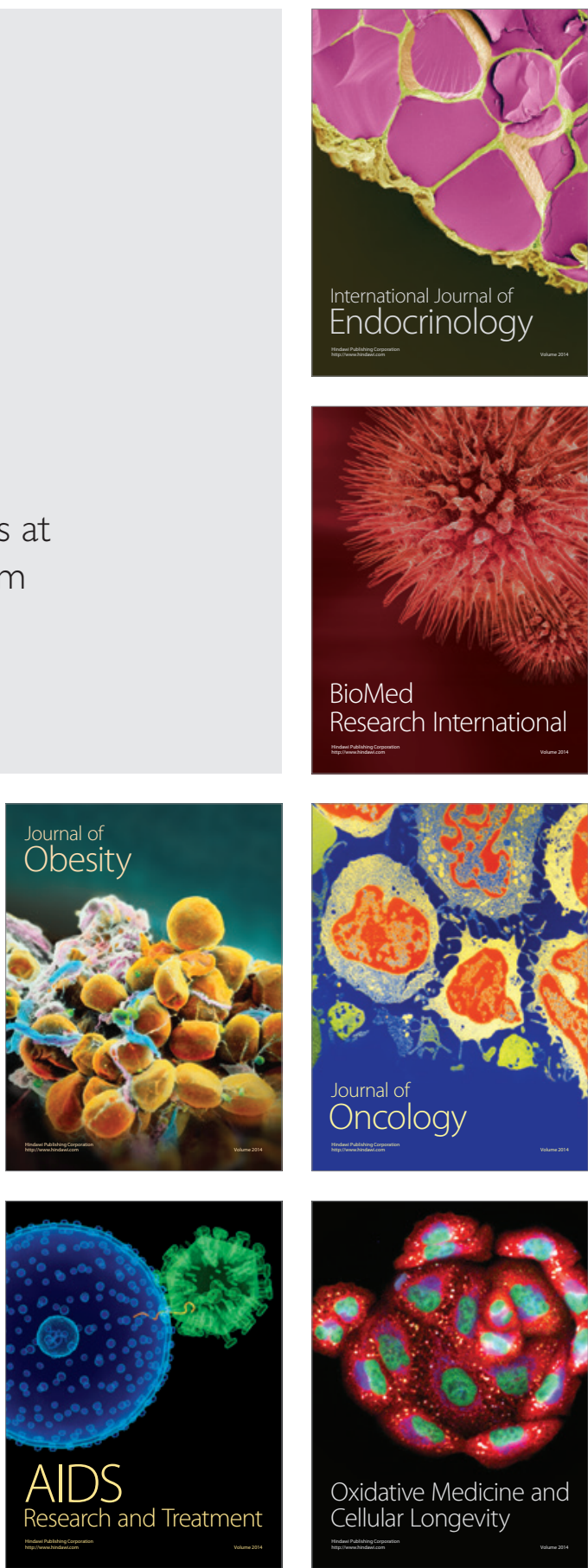